\title{
Modelling the determinants of car-sharing adoption intentions among young adults: the role of attitude, perceived benefits, travel expectations and socio-demographic factors
}

\author{
Ransford A. Acheampong ${ }^{1}$ (D) Alhassan Siiba ${ }^{2}$
}

Published online: 12 July 2019

(C) The Author(s) 2019

\begin{abstract}
Major cities in developing countries are increasingly becoming motorized. Thus, effective solutions to address the negative impacts that come with rising car-ownership are needed as part of an overall travel demand management strategy. In developed and emerging economies, shared-mobility in the form of car-sharing is becoming popular as potentially lowcost and environmentally sustainable alternative to car-ownership. Yet, our understanding of car-sharing adoption and diffusion factors in developing countries is limited. In this study, we fill this gap by examining car-sharing adoption intentions among young adults aged between 18 and 35 years in Ghana, Sub-Saharan Africa. Using structural equation modelling, we model car-sharing adoption intentions based on a framework that integrates individuals' perception of the benefits of car-sharing, attitudes towards the environment and technology, trust of stewardship in car-sharing, perception of innovativeness of carsharing, travel expectations and socio-demographic factors. We found that pro-technology and pro-environmental attitudes correlate positively with perceived benefits of car-sharing. Perceived benefits of car-sharing, in turn, has the largest predictive effect on intentions to car-share. Other factors, including individuals' previous experience using Uber on-demand taxi services, gender, education, driver's licensure and expectation of comfortable and fast travel options, all predict car-sharing adoption intentions. While there exists an interest in both station-based and free-floating car-sharing services, more of the would-be users favour the latter than the former. Also, majority of the potential adopters (62\%) would join a car-sharing service within the first 1 year of its introduction. An important finding is that dissatisfaction with existing public transit services underpins car-sharing intentions, implying that relying on car-sharing alone to meet travel needs, without a holistic strategy of providing quality and affordable public transit services, could lead to unsustainable outcomes.
\end{abstract}

Keywords Shared-mobility $\cdot$ Car-sharing $\cdot$ Collaborative consumption $\cdot$ Mobility-as-aservice · User adoption · Travel behaviour · Ghana

Ransford A. Acheampong

ransfordantwi.acheampong@manchester.ac.uk

Extended author information available on the last page of the article 


\section{Introduction}

Globally, the transportation sector is one of the major sources of pollution, accounting for about 23\% of total energy-related $\mathrm{CO}_{2}$ emissions (EPA 2015; Sims et al. 2014). Reducing private-car ownership, energy consumption and the overall negative impacts of the transportation sector on the environment and society are therefore crucial in the transition towards sustainable urban futures. Eco-innovations, including electric cars, electric bikes and the anticipated deployment of autonomous vehicles could transform motorized transportation in cities, and potentially aid the transition towards more sustainable mobility in the future. Notwithstanding the prospects offered by new technology, there is emerging consensus that hyper-consumerism and increasing ownership of underutilized assets such as the car are no longer sustainable (Botsman and Rogers 2010; Bardhi and Eckhardt 2012). Instead, in the face of rapid urbanization and growing pressures on natural resources, new consumption models, which require fundamental shifts in attitudes and lifestyles, would be needed to address the socio-economic and environmental problems associated with automobile-dependence in cities across the globe (Becker et al. 2015; Shaheen and Cohen 2013).

In recent years, shared-mobility systems, implemented as either station-based or freefloating car-sharing services are becoming popular in many cities (Becker et al. 2015; Shaheen and Cohen 2013; Prieto et al. 2017). The rising popularity and acceptance of shared-mobility is linked to the emerging concept of collaborative consumption: a new paradigm of technology-mediated system of exchange which promotes sharing of underutilized assets such as the car as a low-cost and ecologically-sustainable alternative to ownership (Möhlmann 2015; Botsman and Rogers 2010). With no direct purchasing and maintenance costs involved, and with expenditure on fuel and parking reduced, car-sharing is considered a cost-effective alternative to car ownership (Efthymiou et al. 2013; Ferrero et al. 2017). Car-sharing could also reduce private car-ownership (Liao et al. 2018; Becker et al. 2018), reduce emissions, vehicle mile travel, per capita fuel consumption and demand for parking, thereby reducing travel-induced impacts on the environment and society (Cervero et al. 2007; Rodier 2009; Firnkorn and Müller 2011).

The diffusion of car-sharing services is, however, not a global phenomenon. Instead, as previous studies have shown, car-sharing services are particularly common in cities in Europe, North America and Australia, with new markets emerging in Asian countries including Singapore, China and Japan (see e.g. Shaheen and Cohen 2013; De Lorimier and El-Geneidy 2013; Shaheen and Martin 2010; Ohta et al. 2013; Prieto et al. 2017). Meanwhile, as a result of rising incomes and investments in transport infrastructure, travel demand is expected to increase in developing countries, especially in cities in Africa (Sims et al. 2014). This implies that continued dominance of privately-owned, fossil-fuel-powered cars in these regions will further increase the negative impacts of the transport sector on the environment and society.

In Ghana, for example, car ownership has been increasing in recent years. It is estimated that private vehicle to population ratio increased from 50 vehicles per 1000 population in 2010 to about 70 vehicles per 1000 population in 2015 (Ministry of Transport 2016). Moreover, out of the total fleet of about 1952,564 registered cars as at 2015, 60\% and 14\% were in Accra, the country's capital and Kumasi, the second largest city alone, respectively. One of the main reasons for the rising vehicle ownership in the country's major cities is the huge gap that exists between people's expectations regarding their daily travel experiences on the one hand and the poor quality of existing public transport services, which 
is largely informal and characterised by poor vehicle conditions, lax safety standards and unreliable schedules, on the other hand (Amoh-Gyimah and Aidoo 2013; Esson et al. 2016; Abane 2011). Consequently, as the country's major cities continue to expand outward rapidly (Acheampong et al. 2017; Stow et al. 2013) and vehicle ownership increases, innercity congestion, longer commuting times, journey delays and pollution typify the urban transport situation in Ghana (Armah et al. 2010; Obeng-Odoom 2010; Agyemang 2017; Adarkwa and Poku-Boansi 2011). It is estimated that vehicular emissions alone account for about $70 \%$ of total greenhouse gas emissions in Ghana (World Bank 2009; Peprah et al. 2018).

Although vehicle ownership is on the increase in developing countries, including Ghana, most of them are still in the very early stages of motorization (Cervero 2013; Shaheen and Martin 2010; Kutzbach 2009). At the same time, the rate of adoption of smartphones, one of the platforms enabling mobility-as-a-service solutions such as car-sharing has increased significantly in these countries. It is estimated that about $46 \%$ of the population in developing countries have adopted smartphones (Anthes 2016). In Ghana, it is estimated that with a population of over 25 million people, total mobile phone subscription nationwide was $36,613,987$ in 2016, with an estimated mobile phone penetration rate over the same period being $131.9 \%$ (National Communications Authority 2016). With motorization being in the early stages and smartphone technology adoption increasing rapidly, the potential, exists in these countries to introduce technology-mediated travel alternatives to personal vehicle ownership (Shaheen and Martin 2010).

Indeed, in urban areas of Ghana, for example, new transport services leveraging Information and Communication Technologies (ICT) are already being introduced. Since 2016, Uber has been providing on-demand, ICT-enabled taxi services in the country's major cities, including Accra. The presence of the Uber does not only highlight the existing need for alternative commuting options, but it also shows the potential to address those needs through a portfolio of smart and potentially sustainable transport solutions. However, to date, empirical studies exploring public attitudes towards car-sharing as an alternative to rising car-ownership, individuals' propensity to car-share and the potential of sharedmobility services to become part of the portfolio of sustainable urban transport policies in developing countries, such as Ghana are lacking. Based on evidence from other contexts, we know that consumer acceptance is crucial to successful implementation of sharedmobility systems (see e.g. Nobis 2006; Schaefers 2013). Perhaps, more importantly, is the fact that car-sharing constitutes a new form of mobility that leverages ICT and combines aspects of conventional public transportation and private car use, implying that attitudinal and demographic factors will be important to user acceptance. Despite this, few studies have so far examined the influence of demographic and attitudinal factors on propensity to car-share globally (see e.g. Juschten et al. 2017; Prieto et al. 2017; Ohta et al. 2013; Efthymiou et al. 2013; Sioui et al. 2013; Correia and Viegas 2011).

In view of the aforementioned gaps in the literature, we explore the behavioural influences of user adoption intentions with respect to car-sharing in Ghana, West Africa. In examining user adoption intentions for car-sharing services, we focus on young adults aged between 18 and 35 years in the three most urbanized areas in southern Ghana, namely Accra, the capital; Kumasi, the second largest city; and Sekondi-Takoradi. We do so for two main reasons. Firstly, a combination of factors, including poor quality of existing public transit services and the general believe that car-ownership is a signifier of social status, means that in the absence of reliable alternatives, aspirations for car-ownership tend to be particularly high among young adults. The extent to which this group are willing to use car-sharing to bridge the gap between their travel experiences now and their expectations, 
however, is not clear. Secondly, evidence from previous studies shows that car-sharing, being a new form of technology-enabled mobility, tends to attract young, highly-educated and tech-savvy individuals of moderate and upper incomes living in cities (Le Vine et al. 2014; Efthymiou et al. 2013; Bardhi and Eckhardt 2012; Prieto et al. 2017; Ohta et al. 2013), hence the focus on this demographic in the present study. Focusing on this young demographic group of potential adopters, we deploy a conceptual framework which allows us to model the effects on car-sharing adoption intentions of socio-demographic factors; individuals' expectations with regard to their daily travels; individuals' attitudes towards technology and the environment; and individuals' perception of the innovative characteristic and benefits of car-sharing.

Our main contributions with this study are two-fold. Firstly, this is the first study to examine car-sharing adoption factors in the context of a developing country in Sub-Saharan Africa. Thus, the current study expands the scope of empirical research on shared-mobility into a previously unexplored context, thereby contributing to filling a major knowledge gap in the literature around car-sharing adoption factors in developing countries. Secondly, the study provides practical policy implications for transportation policy in developing countries and beyond. In particular, we show how dissatisfaction with existing public transit services underpins car use intentions through sharing, which, in turn, can also pose wider sustainability challenges in developing economies, if car-sharing schemes are not accompanied with and integrated into efficient and affordable public transit systems.

The remainder of this paper is organized as follows: In section two, we present related literature on collaborative consumption, car-sharing systems and user adoption behaviour. From this review, we advance a conceptual framework of car-sharing adoption behaviour and outline various hypotheses among variables represented in the framework. We discuss the overall methodology employed in this study in section three. The analysis and the discussion of the results of the study, and their policy implications are also presented in sections four and five, respectively followed by our conclusions and an outline of the limitations of the study in section six.

\section{Collaborative consumption, shared-mobility systems and user adoption behaviour}

Shared-mobility constitutes one aspect of the emerging paradigm of technology-mediated exchange of goods and services underlined by economic exchange, reciprocity and efficient utilization of resources (Hartl et al. 2016). Various terminologies, including 'collaborative consumption' (Botsman and Rogers 2010), 'access-based consumption' (Rifkin 2001; Bardhi and Eckhardt 2012) and 'sharing-economy' (see e.g. Sundararajan 2016) have been coined to describe different aspects of this trend of consumption, but with the common theme of reducing waste and pressure on resources while creating economic value for underutilized assets. McLaren and Agyeman (2015), coined the term 'sharing cities' to reflect the convergence of urban space and cyber-space in facilitating equity, inclusiveness, and environmentally efficient consumption models. More recently, the term 'Mobility-asa-Service (MaaS)' has been deployed to encapsulate a new model of mobility distribution that combines different modes to provide a tailored mobility package to customers through a single interface of a service provider (see Jittrapirom et al. 2017; Holmberg et al. 2016; Hietanen 2014). MaaS, represents a shift away from personal ownership of transport modes towards a more need-based, on-demand mobility solutions in cities. 
In their typology of collaborative consumption systems, Botsman and Rogers (2010), capture car-sharing under what they refer to as 'product service system': a collaborative consumption model that enables people to pay for the benefits of products without themselves bearing the financial costs and/or other responsibilities associated with outright ownership. Thus, with car-sharing services, commuters, instead of purchasing their own cars, register with a company, (either publicly or privately run), providing a fleet of cars and book to use a car when it is needed. The service could be run as 'station-based' systems, where consumers make reservation for and pick cars located at fixed stations, and are required after use to return the car to the same station. Station-based systems may offer one-way or round-trip car-sharing services (Correia et al. 2014). Car-sharing services are also being implemented as 'free-floating' systems, where customers are able to check the availability and location of cars online using a computer or smartphone (Firnkorn and Müller 2011). Free-floating systems are a lot more flexible because reservations are not required and at the end of the ride, customers can park cars in permissible parking spaces within the car-sharing service area (Becker et al. 2017). By eliminating the restrictions of having to set predefined stations as trip origins and destinations, free-floating car-sharing offers fast and convenient travel and thus, appeals to both public transit and private car users (Becker et al. 2017).

\section{User adoption behaviour in car-sharing}

Like other travel-related choices, individuals' propensity to car-share is influenced by a number of factors, including socio-psychological and socio-demographic factors (Correia and Viegas 2011; Prieto et al. 2017; Efthymiou et al. 2013). From a socio-psychological perspective, car-sharing adoption could be considered a choice under volitional control for which individuals' attitudes are important. In Ajzen's theory of planned behaviour (Ajzen 1991), attitude is posited as one of the key proximal determinants of behavioural intentions. Attitude reflects an individual's expectations of all the outcomes of a choice behaviour and the personal values they attach to those outcomes (Ajzen 1991). Attitudes could be affective, representing a person's feelings or emotions about the attitude object or instrumental, reflecting the extent to which the individual believes that taking a particular decision would be beneficial or advantageous (Armitage and Conner 2001). In relation to car-sharing, an individual's attitude would reflect their evaluation of what the positive and negative outcomes of car-sharing would be. Consequently, travel mode choice considerations including flexibility, convenience and affordability have been found to influence adoption decisions (Becker et al. 2017; Bardhi and Eckhardt 2012).

Moreover, existing models of innovation acceptance and diffusion have demonstrated that user adoption decisions are influenced by a number of factors operating at the individual level as well as attributes of the object of choice (i.e. new technology or innovation). In Davis' (1985) model, 'perceived usefulness', which reflects an individual's belief of the extent to which adopting a new innovation will enhance the performance of specific tasks or activities, is considered one of the key determinants of user acceptance and adoption of new products. In relation to car-sharing, perceived usefulness may reflect the individual's beliefs of what the commuting benefits of car-sharing would be as opposed, for example, to using existing public transport services or owning a car. Indeed, the evidence suggests that convenience, flexibility, comfort, speed (Juschten et al. 2017; Becker et al. 2015; Correia et al. 2014) as well as cost saving-benefits (Mont 2004; Bardhi and Eckhardt 2012; 
Lamberton and Rose 2012) are some of the key determinants of participation in car-sharing services.

Furthermore, we know, from Rogers' technology diffusion model that within the population, user adoption decisions regarding innovation do occur over different time horizons and are linked to individuals' changing perceptions and attitudes towards innovation as well as their perception of the innovation characteristics of the new product in question (Rogers 2000). Given that technology has been a key driver of shared-mobility, especially with free-floating car-sharing, perceptions and attitudes towards technology would most likely influence user adoption decisions. Indeed, previous empirical studies have shown that membership of car-sharing services tends to be younger, highly educated, affluent and tech-savvy individuals (Burkhardt and Millard-Ball 2006; Efthymiou et al. 2013; Le Vine et al; 2014).

Car-sharing is seen as an environmentally sustainable alternative to car ownership (Hamari et al. 2016). Yet, the assertion that ecological sustainability convictions underpin car-sharing adoption (Burkhardt and Millard-Ball 2006) is not conclusive. For both stationbased and free-floating car-sharing services, Becker et al. (2017), found that users were not motivated by environmental sustainability convictions, but instead, by openness to new and innovative services. Indeed, some proponents of the collaborative consumption paradigm have suggested that for some participants, sustainability concerns are often of secondary importance (Barnes and Mattsson 2016), implying that ecological benefits emerge as unintended consequences of sharing (Botsman and Rogers 2010). That notwithstanding, it would be useful to examine the links between overall attitudes towards environmental sustainability and car-sharing user adoption intentions given that motorized travel choices have environmental consequences.

In summary, the nature of travel choices in general, and car-sharing adoption in particular, implies that cross-cutting attitudinal factors interplay with socio-demographic characteristics of individuals to influence decisions. In the next section, we advance a conceptual framework based on insights from existing theoretical models and empirical research, which we subsequently deploy to model car-sharing adoption intentions among young adults in Ghana.

\section{Conceptual model and hypotheses}

The conceptual model we advance to model car-sharing adoption intentions integrate seven latent concepts and socio-demographic factors (see Fig. 1). The framework shows hypothesized relationships among the study variables. We depict nine pairs of hypothesized associations, using double-headed arrows, which implies that the variables in question are postulated to vary in correlation with each other. Direct effects, which indicate the predictive effect of one variable on the other are shown with single-headed arrows. There are seven hypothesized direct effects in the conceptual model.

Given that travel choices have environmental consequences, we hypothesize that individuals' attitude towards the environment will covary with their perception of the benefits of carsharing. Similarly, attitudes towards technology and innovation are postulated to covary with perceived benefit of car-sharing, given that car-sharing leverages ICT to provide on-demand travel services to customers. Moreover, in our conceptual framework, we capture individual's perception of the innovativeness of car-sharing and posit that these perceptions will covary with technology attitudes and perceived benefits of car-sharing, respectively. We include travel mode choice considerations and individual's satisfaction with their current travel modes in the 


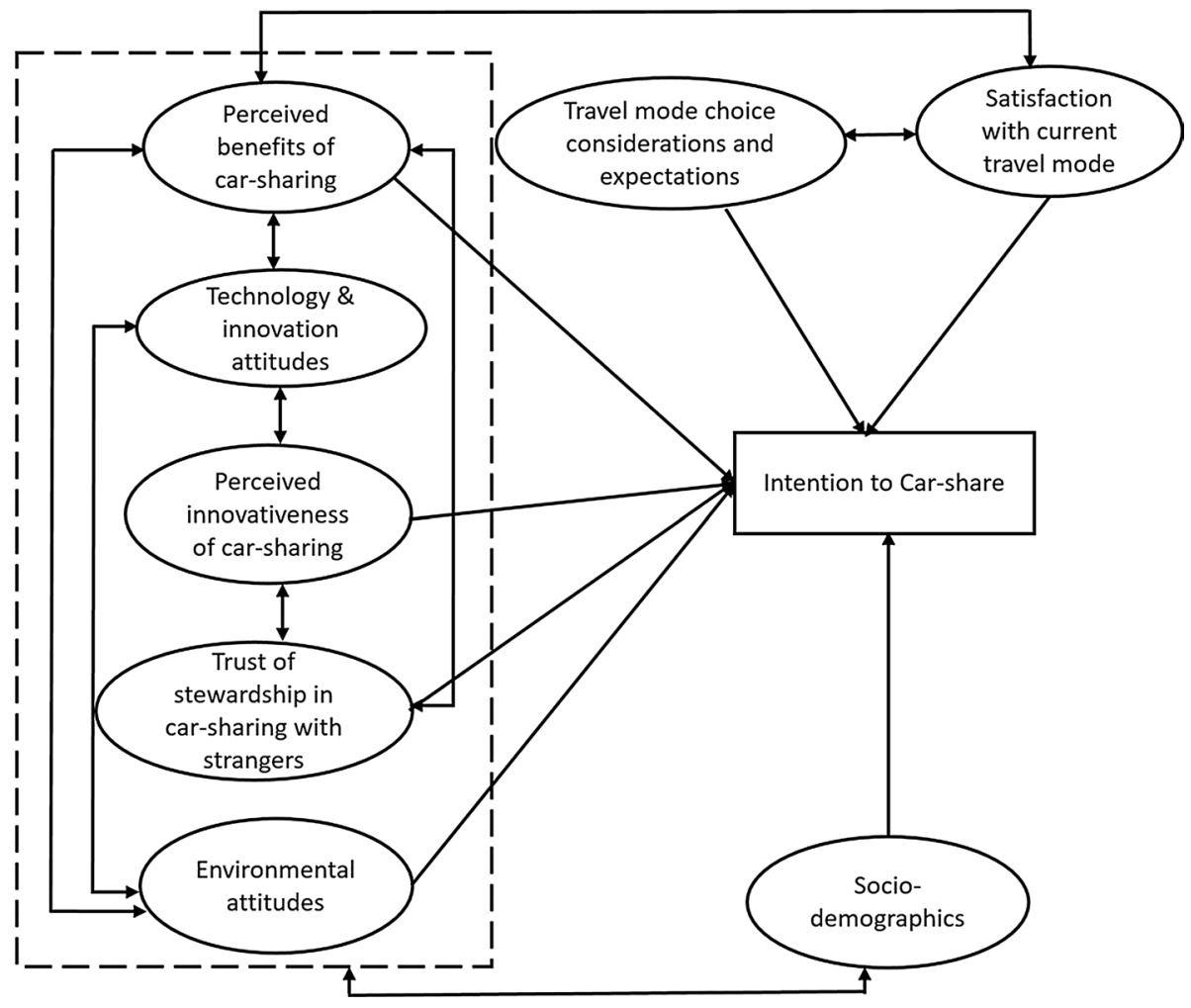

Fig. 1 Conceptual framework of car-sharing adoption intentions

conceptual model. Together, these concepts are intended to reflect the possible gaps between individuals' expectations regarding their daily travel expectations on the one hand and their experiences on the other hand. The assumption here is that, the experience-expectation gap could serve as a useful reference point for individuals to evaluate their perception of the overall benefits of car-sharing. We therefore hypothesize that travel mode choice expectations/ considerations and satisfaction with current travel modes will each, directly predict intension to car-share. Finally, since car-sharing involves using a fleet of cars with other strangers, we incorporate in our conceptual framework the concept of trust of stewardship in car-sharing as perceived by would-be users of this mobility service. We hypothesize that trust of stewardship will covary with perceived benefits of car-sharing and also have direct predictive effect on carsharing adoption intentions.

In the section that follows, we present the research methodology, which involved questionnaire design, data collection and statistical modelling techniques. 


\section{Methodology}

\section{Survey design and data collection}

We adopted a cross-sectional survey design for this research. As explained and justified in the introduction section, the targeted participants for this study were young adults living in the three major urban settlements in Ghana, namely Accra, Kumasi and Sekondi-Takoradi. We define young adults in this study as individuals aged between 18 and 35 years, following definitions contained in the national constitution of Ghana and the National Youth Policy.

We designed a structured questionnaire based on the variables represented in the conceptual framework of car-sharing adoption intentions (see Fig. 1). Response items of the framework concepts were presented in three themes to the survey respondents. The first theme of the questionnaire covered socio-demographic information and current travel characteristics of the respondents. The survey respondents were asked to indicate their main travel modes for their most recent work and school trips and the estimated travel times of the trips. In addition, the respondents were asked to indicate, on a five-point Likert scale, the level of importance they attach to five factors namely, comfort, flexibility, privacy, travel speed and affordability, which together reflect what they expect to have from the various transportation services they use. The study participants were also asked to indicate their overall satisfaction with the travel modes they used for their most recent school or work journey. The second theme of the questionnaire comprised indicator items that we used to measure respondents' attitudes. We formulated response items for attitudes towards the environment and technology and innovation and presented them to the participants to evaluate on a Five-point Likert scale, ranging from 1 (Strongly disagree) to 5 (Strongly agree).

In the third thematic section of the questionnaire, we focused on the concept of carsharing. As we will later show in the results section, most of the study respondents were either hearing of car-sharing for the first time or knew very little about shared-mobility services in general. In view of this, we first introduced the concept of car-sharing, providing a detailed description of the concept and its operational characteristics. We also explained in the questionnaire, the two main types of car-sharing, namely 'station-based' and 'freefloating' car-sharing. Following the description of the concept of car-sharing, we presented a series of response items to elicit our participants' perception of the benefits and innovativeness of car-sharing and whether or not they would trust to car-share with other people, on a five-point Likert Scale ranging from 1 (Strongly disagree) to 5 (Strongly agree). Next, we asked the respondents to indicate whether they "intend to join a car-sharing scheme if it were available in your city". We elicited the responses to this item on a five-point Likert Scale ranging from 1 (Definitely no) to 5 (Absolutely yes).

In the context of this study, trust was used to reflect the stewardship implications of using a communal asset in the form of car-sharing (see Bardhi and Eckhardt 2012), but not in the sense of having to couple with other strangers on a journey in the same car, as is the case with ridesharing or conventional taxi and public transit. Thus, we asked our respondents to indicate whether or not they trust that strangers with whom they would car-share, will take good care of the cars to ensure best possible service quality. Moreover, the potential benefits of car-sharing included the respondents' perception of its usefulness for both 
commuting and non-commuting trips. As previous studies have shown, in the three major cities represented in this study, suburban to inner-city and within inner-city commuting flows tend to cover relatively shorter distances. For example, in Kumasi, the second largest metropolis, previous research suggests an average work-trip distance of $4.5 \mathrm{~km}$ (Acheampong 2017). Similarly, in Accra, the capital city, a recent study by Agyemang (2017) found that a significant proportion of intra-urban commuting is within the 5-9 km range. Thus, given these distances, the potential exists for car-sharing services to meet both commuting and non-commuting trip purposes.

To explore our respondents' adoption intentions regarding car-sharing further, we asked their opinions regarding whether or not they would like to join a station-based car and/ or free-floating car-sharing. We also asked our respondent whether or not they would use car-sharing services during day time (i.e. between 6 am and $6 \mathrm{pm}$ ) or evening times (i.e. after $6 \mathrm{pm}$ ). Moreover, in order to capture the temporal aspects of the car-sharing adoption decisions in the population, we asked our respondents to choose from three options, which reflect when they would like to join a car-sharing scheme if it were to become available in their city. As the aim was not to administer a stated-preference survey with defined attributes for possible alternatives, the aforementioned items were not constrained into discrete choices and presented to the survey respondents. Instead, we included these items in the questionnaire as exploratory questions aimed at gaining deeper understanding of the respondents' adoption intentions.

The survey questionnaire was hosted online and distributed to the respondents via a variety of platforms including sending direct emails and/or sharing the link to the survey on social media (i.e. LinkedIn, Twitter and Facebook). We also encouraged our respondents to forward the survey to other individuals in their network. ${ }^{1}$

\section{Statistical analyses}

We model car-sharing adoption intentions using Structural Equation Modelling (SEM) technique. Firstly, we test overall scale and sub-scale item reliability and consistency for indicator items of latent variables in our model by computing Cronbach's Alpha reliability coefficient $(\alpha)$. Next, we specify the measurement and structural models and evaluate model fit using model identification indices namely: the Chi square statistic $\left(\chi^{2}\right)$ and Normed Chi square $\left(\chi^{2} / \mathrm{df}\right)$; Normed Fit Index (NFI); Comparative Fit Index (CFI); Tucker-Lewis Index (TLI); Incremental fit index (IFI); and Root Mean Square Error of Approximation (RMSEA). NFI, CFI, TLI and IFI values $\geq 0.90$ indicate acceptable model fit, while RMSEA value of 0.01, 0.05, and 0.08 indicate excellent, good, and mediocre fit, respectively (see Kline 2015). The SEM analysis was performed using AMOS 21 software in SPSS.

\footnotetext{
${ }^{1}$ The estimated population of 3,954,883 individuals aged between 18 and 35 years (Ghana Statistical Services 2014) constituted our sample frame. Based on this figure, an estimated minimum sample size of 600 persons at $95 \%$ confidence level was required to make our findings representative, tolerating a $4 \%$ margin of error. In accordance with size of the sample frame in Accra, Kumasi and Sekondi-Takoradi, we aimed for, at least $40 \%, 35 \%$ and $25 \%$ of the responses to come from Accra, Kumasi and Sekondi-Takoradi respectively.
} 


\section{Results}

\section{Summary of respondents' background socio-demographics and travel characteristics}

The online survey attracted 700 respondents. Out of this total, 647 valid responses remained for analysis after cleaning the data. ${ }^{2}$ We present descriptive summary of the background socio-demographic information and travel characteristics of the survey respondents in Table 1. About $40 \%$ and $36 \%$ of our respondents live in Accra and Kumasi, respectively while the remaining $24 \%$ live in Sekondi-Takoradi. The average age of our respondents is 29 years. Out of the total sample, males constitute 52\%. Most of the study respondents are university-educated, who have completed a bachelor's degree/diploma (58\%) or a Postgraduate degree (39\%). Our respondents earn an average monthly salary of GH $₫ 1800$ (US\$400), which is higher than the average monthly income of GH $\not 1387$ (US\$309) in Ghana as reported by the Ghana Living Standards Survey. ${ }^{3}$

With respect to travel mode choice for their reference school or work trips, the results of the survey show that more than half of our respondents used public transport in the form of mini-bus/Trotro (37\%), ${ }^{4}$ bus $(4 \%)$ or taxi $(13 \%)$ while about $34 \%$ of them used private cars, either driving alone (19\%) or car-pooling with other members of their household (15\%). Only $6 \%$ of work and school trips were undertaken using non-motorized transport (i.e. walking and bicycling). In addition, nearly half of our respondents reported having a valid driver's license, despite only less than a quarter driving their own cars. There is an almost equal proportion of driver's licence holders among the respondents who are male $(51 \%)$ and female $(49 \%)$.

Moreover, we asked our respondents how much they knew about car-sharing before they took the online survey. Whereas 53\% of the respondents reported that the concept of carsharing was completely new to them prior to taking the survey, $37 \%$ of them indicated that they have some knowledge about car-sharing as a new form of mobility. Indeed, $30 \%$ of the respondents reported that they have used Uber's on-demand taxi services, at least once in their respective cities prior to taking our survey.

\section{Summary of responses to Likert scale items}

In this section, we present the results of the study participants' responses to the indicator items used to measure the latent variables presented earlier in our conceptual model (see Fig. 1). Descriptive summary of the responses, which were elicited using a five-point Likert scale, is presented in Table 2.

The response items evaluated by our respondents with respect to the perceived benefits of car-sharing reflect three broad potential outcomes of using this new form of mobility.

\footnotetext{
2 The data cleaning involved removing incomplete responses as well as responses from participants who did not fall within the targeted age group of 18 and 35 years and/or respondents who were living in cities other than Accra, Kumasi and Sekondi-Takoradi.

3 The Ghana Living Standards Survey Round 6 (GLSS6) provides the most recent data on income levels in Ghana. The survey report published in 2014 is based on a national sample of 16,772 households. According to the GLSS6, the lowest and highest quintile monthly earnings in Ghana are GHф546 (US\$121) and $\mathrm{GH} \notin 2100$ (US\$467), respectively.

${ }^{4}$ In Ghana, Trotro are 10-19-seater privately owned minibuses used as public transport.
} 
Table 1 Characteristics of the survey participants $(n=647$, unless otherwise stated)

\begin{tabular}{|c|c|c|}
\hline \multirow[t]{3}{*}{ City location of respondents } & Accra & $40 \%$ \\
\hline & Kumasi & $36 \%$ \\
\hline & Sekondi-Takoradi & $24 \%$ \\
\hline Gender & Female: Male & $48 \%: 52 \%$ \\
\hline Age & Average age & 29 years $(\mathrm{SD}=3.45)$ \\
\hline \multirow[t]{2}{*}{ Marital status } & Married: Single & $34 \%: 66 \%$ \\
\hline & Respondents with children & $26 \%$ \\
\hline \multirow[t]{3}{*}{ Educational attainment } & Senior High School & $3 \%$ \\
\hline & Tertiary (Bachelor's/Diploma) & $58 \%$ \\
\hline & Postgraduate (Master's degree or higher) & $39 \%$ \\
\hline \multirow[t]{4}{*}{ Employment } & Employed & $73 \%$ \\
\hline & Unemployed & $8 \%$ \\
\hline & Student & $18 \%$ \\
\hline & Home-based: Non-home-based employment & $11 \%: 89 \%(n=438)$ \\
\hline \multirow[t]{3}{*}{ Income (Monthly) } & 25th Percentile & $\mathrm{GH} \varnothing 1200.00$ \\
\hline & 50th Percentile & $\mathrm{GH} \phi 1800.00$ \\
\hline & 75th Percentile & $\mathrm{GH} \varnothing 3000.00$ \\
\hline \multirow[t]{7}{*}{ Travel mode work/school $(n=546)$} & Private-car (Driving alone) & $19 \%$ \\
\hline & $\begin{array}{l}\text { Private-car (Car-pooling with household } \\
\text { members) }\end{array}$ & $15 \%$ \\
\hline & Public transport (Mini-bus/Tro-tro) & $37 \%$ \\
\hline & Public transport (Bus) & $4 \%$ \\
\hline & Public transport (Taxi) & $13 \%$ \\
\hline & Motorcycle & $7 \%$ \\
\hline & Non-motorized (Walking/cycling) & $6 \%$ \\
\hline Satisfaction with travel mode & Satisfied: Not-satisfied & $47 \%: 53 \%$ \\
\hline \multirow[t]{3}{*}{ Travel time to work/school $(n=546)$} & $30 \mathrm{~min}-1 \mathrm{~h}$ & $35 \%$ \\
\hline & $1-2 \mathrm{~h}$ & $54 \%$ \\
\hline & $3-4 h$ & $11 \%$ \\
\hline Driver's License & Yes: No & $47 \%: 53 \%$ \\
\hline \multirow[t]{3}{*}{ Knowledge of car-sharing } & No knowledge & $53 \%$ \\
\hline & Some knowledge & $37 \%$ \\
\hline & A lot of knowledge & $10 \%$ \\
\hline
\end{tabular}

The first set of outcomes relate to the potential benefits of car-sharing in the form of reducing car ownership and the associated negative impacts on the environment. Results of the survey show that the majority of our respondents agree that car-sharing is a good alternative to car-ownership (62\%) and that having this new form of mobility would reduce the need for a personal vehicle (58\%). About seven in 10 of our respondents agree that car-sharing would contribute to reducing traffic congestion in their respective cities. With respect to the potential benefits in reducing travel-related environmental pollution through car-sharing, however, $37 \%$ of the respondents agree to the likelihood of this outcome while the majority of the respondents (i.e. 46\%) were indifferent. The second group of items measuring the benefits of car-sharing reflect the participants' perception of the suitability of car-sharing for different trip purposes. More than half (54\%) and 47\% of the respondents agree that car-sharing would be suitable for work journeys and non-work journeys such as 


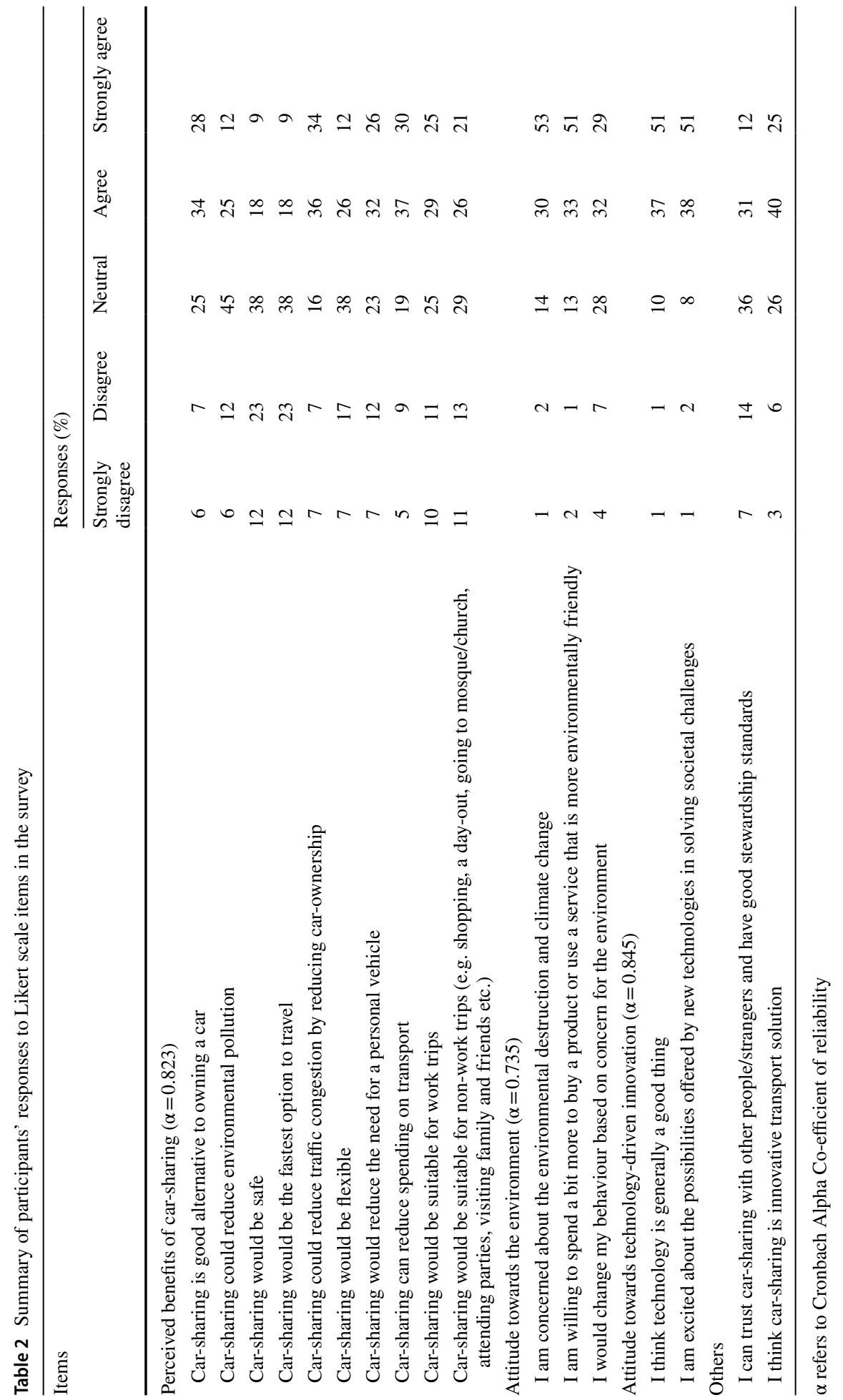




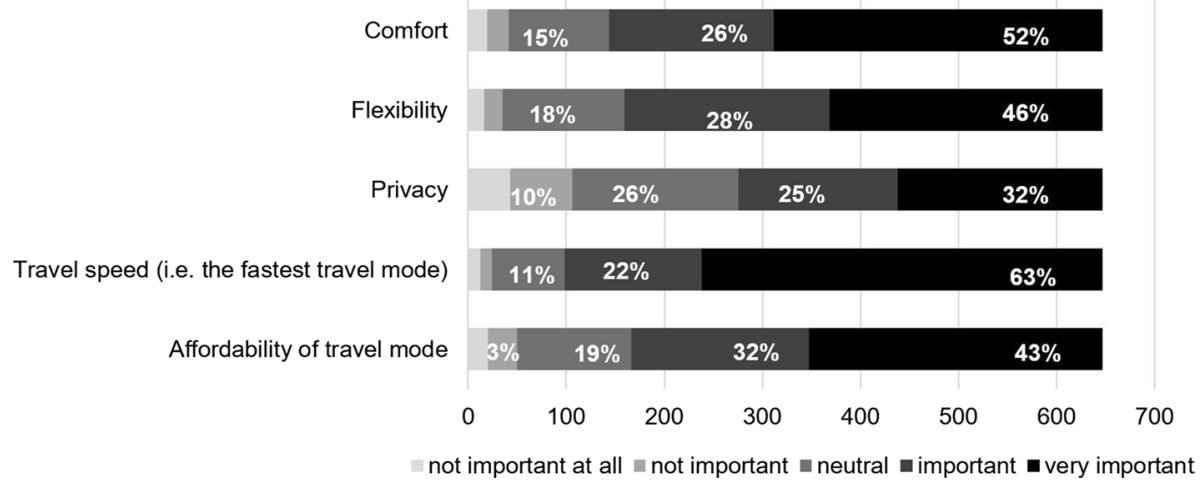

Fig. 2 Summary of individuals' responses to items measuring travel mode choice considerations and expectations

shopping, attending church, visiting friends and family, respectively. The third category of potential benefits of car-sharing evaluated by the respondents capture potential commuting benefits in the form of perception of safety, flexibility and travel cost savings through carsharing. With respect to safety and flexibility as likely commuting benefits of car-sharing, the majority of the respondents (38\% for both response items) are indifferent while $27 \%$ agree those outcomes are likely. About two-thirds of the respondents', however, agree that they would reduce spending on travel by using car-sharing. Overall, the results show that the majority of our respondents perceive car-sharing as being a good alternative to carownership that could bring positive commuting benefits.

In addition to the perceived benefits of car-sharing, we elicited responses that reflect our respondents' attitude towards the environment, technology and innovation. The results show overall positive attitude towards the environment, as about $83 \%$ of the respondents agree that they are concerned about the destruction of the environment and the associated problem of climate change. Nearly two-thirds would change their behaviour based on their concern about environmental impacts of human activities. Moreover, $84 \%$ of our respondents agree that they would spend extra money on consuming goods and services that are more environmentally friendly. Overall attitude toward technology and innovation is also high among the respondents. About $88 \%$ and $89 \%$ of the respondents indicated that advances in technology and innovation is generally a positive thing and that they are excited about the possibilities such new technologies offer in addressing societal challenges.

In our conceptual model, we posited that individuals' expectations and overall satisfaction with respect to their daily travel modes would be relevant in examining whether or not they would use new mobility services such as car-sharing. In view of this, we asked our respondents to indicate the extent to which they consider factors namely, comfort, flexibility, privacy, travel speed and affordability important in choosing a travel mode. The results (see Fig. 2) show that a significant proportion of the respondents expected their travel mode to be comfortable (78\%), affordable (75\%), fast (85\%) and offer flexibility in travel $(74 \%)$. The need for privacy did not emerge as an important expectation among $26 \%$ and $17 \%$ of the respondents who indicated indifference and disagreed to this response item, respectively; about 59\% of the respondents, however, agree that privacy is important to them in their daily travel choices. With respect to overall satisfaction with travel mode they used for their most recent work or school journey, the results show that more than half 
Fig. 3 Summary of individuals' responses to item measuring intention to use car-sharing

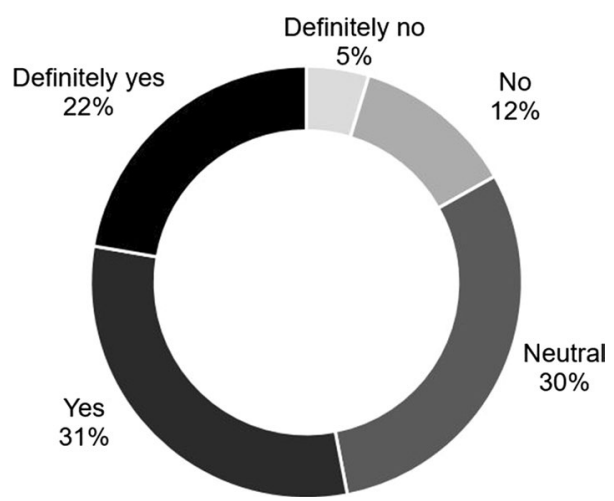

of the respondents (53\%) are dissatisfied with their reference mode of transportation. Our survey results further show that public transport users are more likely to be dissatisfied than private car users, as about $70 \%$ of the former group compared to only $16 \%$ of the latter group indicated that they were not satisfied with their travel experience. The aforementioned association is statistically significant $\left(\chi^{2}=156.401, \mathrm{df}=1 ; p<0.001\right.$; Cramer's V effect size $=0.510, p<0.001$ ), with odds ratio estimates further revealing that public transport users are about 13 times more likely to be unhappy with their transport mode experiences compared to car users.

As shown in Table 1, on the issue of trusting others to be good stewards in a communal sharing system, about $43 \%$ of our respondents agree that they could trust strangers with whom they would likely car-share in this regard; a further $35 \%$ were indifferent about this. On perception of innovation characteristics of car-sharing as new form of mobility, a significant percentage of our respondents (i.e. 75\%) agree that car-sharing is an innovative transport solution. In addition to the above, we show in Fig. 3 that our respondents' opinions regarding whether or not they intend to join a car-sharing service if it were available in their city. The results show that more than half will intend to use this service. Whereas $17 \%$ of the respondents indicated that they have no intention of using car-sharing, about $30 \%$ of them are not sure if they would join this mobility scheme.

The results of further exploratory questions, regarding whether or not our respondents who indicated intent of using car-sharing, would join station-based and free-floating carsharing services, as well as the time period over which they are likely to use the service following its introduction are summarised in Fig. 4. Firstly, asked whether or not they would join a station-based car-sharing assuming this type of service were to become available in their city, two-thirds of potential users indicated that they would definitely do so while the remaining $34 \%$ indicated that they would probably use station-based car-sharing (see Fig. 4a). Next, would-be users were asked, following a description of free-floating car-sharing, whether or not they would use this type of car-sharing service, assuming it were available in their city. Our results show that the percentage of would-be users who indicated that they would definitely use free-floating car-sharing service increased to $71 \%$. Also, a greater percentage of our respondents who intend to participate in car-sharing (i.e. $82 \%$ ) would definitely use the service during the day-time between the hours of $6 \mathrm{am}$ and $6 \mathrm{pm}$. On the likelihood of using the service during the evening (i.e. the hours after $6 \mathrm{pm}$ ), 

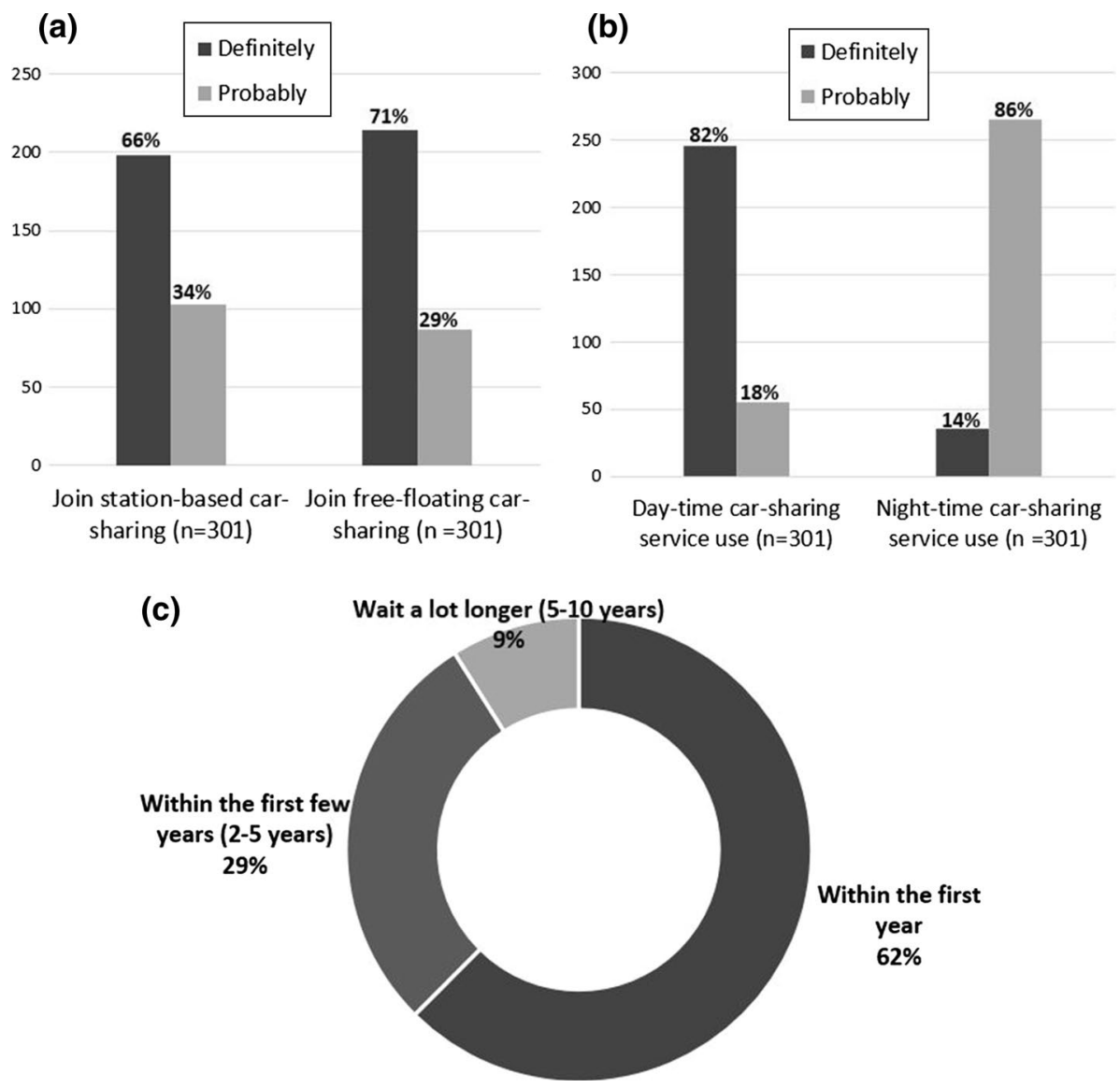

Fig. 4 Summary of individuals' responses to items measuring: a interests in station-based and free-floating car-sharing services; $\mathbf{b}$ likelihood of car-sharing during day-time and evening-time; and $\mathbf{c}$ intended adoption periods following introduction of car-sharing services (Respondents who initially indicated that they would want to use car-sharing services subsequently responded to this item. For each service type (i.e. stationbased and free-floating car-sharing), all the potential users of carsharing $(n=301)$ were asked to choose one of two answers, 'definitely yes' or 'probably yes')

majority of our respondents (i.e. 83\%) who have interest in car-sharing indicated that they would definitely not use this mode of transportation (see Fig. 4b).

Finally, the temporal aspects of individuals' car-sharing adoption intentions, which also partially reflect potential adoption levels in the diffusion cycle of service are examined. Results of the survey show that most of our respondents who expressed interest in using car-sharing services (i.e. 62\%) would join a service within the first 1 year of it becoming available in their city (see Fig. 4c). About $29 \%$ of potential users would participate in car-sharing within the first 2-5 years of its introduction, the remaining $9 \%$ would wait a lot longer, after 5 years or more, before joining a car-sharing service in their respective cities. Overall, results on the potential times horizons of adoption intentions outlined above, suggest a potentially large early-adopter threshold population that could provide the critical-mass needed to sustain the service. 


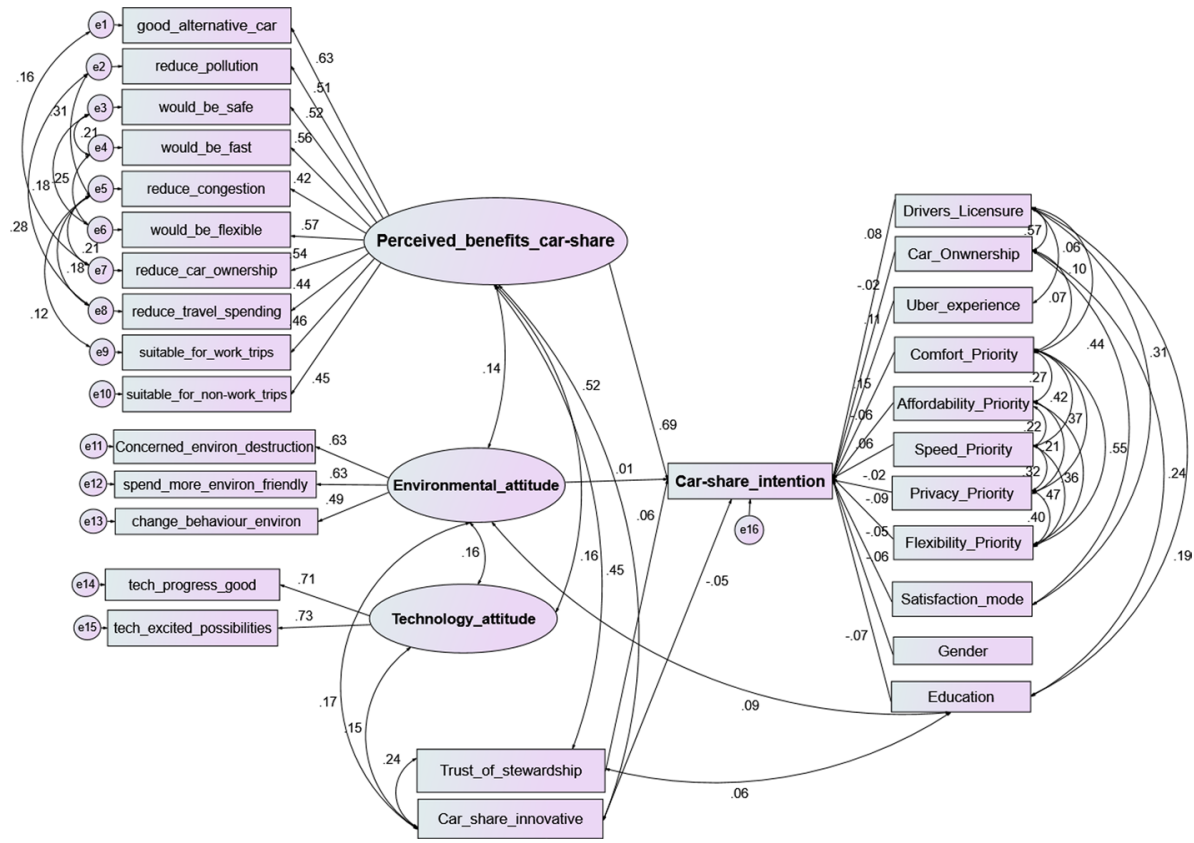

Fig. 5 Path diagram of SEM of car-sharing adoption intention. Model identification indices: $\chi^{2}=713.033$, $\mathrm{df}=339, \quad$ Normed $-\chi^{2}=2.103, \quad p<0.01 ; \quad$ RMSEA $=0.041 ; \quad$ NFI $=0.900 ; \quad$ CFI $=0.907 ; \quad$ IFI $=0.908$; $\mathrm{TLI}=0.901$. Overall scale reliability of latent response items $(\alpha)=0.801$

\section{Modelling the determinants of user adoption intentions for car-sharing}

In modelling the determinants of car-sharing adoption intentions, we specify a SEM. The outcome variable in the model is respondents' opinions regarding whether or not they would join car-sharing service, which we presented in Fig. 3. The explanatory variables in the model comprise socio-demographic factors, and the Likert scale response items which we have presented in Table 2 and Fig. 2. The path diagram of the model is presented in Fig. 5. In our SEM of car-sharing adoption intentions, we establish several pairs of association and direct effect relationships between variables (see Table 3). Below, we present the results of associations between variables first, followed by that of the direct predictive effects.

The SEM results show a positive association between pro-technology attitudes and proenvironmental attitudes. There is a significant relationship between educational attainments and pro-environmental attitudes, although the size of the effect is small. We also found that perceived benefits of car-sharing correlates positively with both pro-environmental and pro-technology attitudes, suggesting that individuals having these positive attitudes are more inclined to agree that, ICT-mediated car-sharing service could be a good alternative to car-ownership, thereby helping to reduce car ownership, congestion and pollution, while bringing potential travel cost saving benefits, among others. Moreover, results of the SEM show that individuals with positive attitude towards technology also tend to agree that carsharing is an innovative new model of travelling. Perception that car-sharing is innovative, in turn, correlates positively with perceived benefits of car-sharing. We also found that 
Table 3 Correlations, covariance and regression weights of relationships among variables in SEM of carsharing adoption intention

\begin{tabular}{|c|c|c|c|c|c|}
\hline Direct effects & $\beta$ & $\mathrm{B}$ & $\mathrm{SE}$ & $\mathrm{CR}$ & $\mathrm{P}$ \\
\hline Car-share-intention $\leftarrow$ Perceived-benefits-car-share & 1.581 & 0.690 & 0.150 & 10.511 & **** \\
\hline Car-share-intention $\leftarrow$ Environmental-attitude & 0.023 & 0.011 & 0.086 & 0.270 & 0.787 \\
\hline Car-share-intention $\leftarrow$ Trust-of-stewardship & 0.061 & 0.061 & 0.037 & 1.632 & 0.103 \\
\hline Car-share-intention $\leftarrow$ Car-sharing-innovative & -0.051 & -0.049 & 0.042 & -1.220 & 0.222 \\
\hline Car-share-intention $\leftarrow$ Uber-experience & 0.123 & 0.114 & 0.032 & 3.835 & **** \\
\hline Car-share-intention $\leftarrow$ Satisfaction-current-mode & -0.054 & -0.054 & 0.033 & -1.606 & 0.108 \\
\hline Car-share-intention $\leftarrow$ Affordability-travel-priority & -0.068 & -0.060 & 0.036 & -1.874 & 0.041 \\
\hline Car-share-intention $\leftarrow$ Comfort-travel-priority & 0.176 & 0.145 & 0.045 & 3.907 & $* * *$ \\
\hline Car-share-intention $\leftarrow$ Speed-travel-priority & 0.084 & 0.061 & 0.048 & 1.749 & 0.03 \\
\hline Car-share-intention $\leftarrow$ Flexibility-travel-priority & -0.105 & -0.091 & 0.045 & -2.320 & 0.02 \\
\hline Car-share-intention $\leftarrow$ Privacy-travel-priority & -0.017 & -0.017 & 0.034 & -0.519 & 0.603 \\
\hline Car-share-intention $\leftarrow$ Gender & -0.065 & -0.064 & 0.030 & -2.146 & 0.032 \\
\hline Car-share-intention $\leftarrow$ Education & -0.062 & -0.069 & 0.028 & -2.186 & 0.029 \\
\hline Car-share-intention $\leftarrow$ Driver-licensure & 0.081 & 0.080 & 0.037 & 2.179 & 0.029 \\
\hline Car-share-intention $\leftarrow$ Car-ownership & -0.017 & -0.015 & 0.043 & -0.393 & 0.694 \\
\hline Correlations and covariance & Cov & Corr & $\mathrm{SE}$ & CR & $\mathrm{P}$ \\
\hline Perceived-benefits-car-share $\longleftrightarrow$ Environmental-attitude & 0.007 & 0.145 & 0.003 & 2.584 & 0.01 \\
\hline Perceived-benefits-car-share $\longleftrightarrow$ Technology-attitude & 0.019 & 0.169 & 0.006 & 3.291 & $* * *$ \\
\hline Perceived-benefits-car-share $\longleftrightarrow$ Trust-of-stewardship & 0.048 & 0.448 & 0.006 & 8.207 & $* * *$ \\
\hline Perceived-benefits-car-share $\longleftrightarrow$ Car-sharing-innovative & 0.053 & 0.518 & 0.006 & 8.991 & $* * *$ \\
\hline Car-sharing-innovative $\longleftrightarrow$ Technology-attitude & 0.071 & 0.150 & 0.022 & 3.272 & 0.001 \\
\hline Technology-attitude $\longleftrightarrow$ Environmental-attitude & 0.038 & 0.160 & 0.015 & 2.590 & 0.01 \\
\hline Technology-attitude $\longleftrightarrow$ Perceived-benefits-car-share & 0.034 & 0.158 & 0.011 & 3.193 & 0.001 \\
\hline Trust-of-stewardship $\longleftrightarrow$ Car-sharing-innovative & 0.057 & 0.240 & 0.009 & 6.024 & $* * *$ \\
\hline Comfort-travel-priority $\longleftrightarrow$ Satisfaction-current-mode & 0.007 & 0.036 & 0.007 & 1.129 & 0.259 \\
\hline Satisfaction-current-mode $\longleftrightarrow$ Affordability-travel-priority & 0.005 & 0.024 & 0.007 & 0.749 & 0.454 \\
\hline Satisfaction-current-mode $\longleftrightarrow$ Car-ownership & 0.101 & 0.441 & 0.010 & 10.514 & $* * *$ \\
\hline Speed-travel-priority $\longleftrightarrow$ Flexibility-travel-priority & 0.073 & 0.470 & 0.007 & 10.808 & $* * *$ \\
\hline Affordability-travel-priority $\longleftrightarrow$ Flexibility-travel-priority & 0.066 & 0.351 & 0.008 & 8.412 & $* * *$ \\
\hline Affordability-travel-priority $\longleftrightarrow$ Privacy-travel-priority & 0.045 & 0.208 & 0.009 & 5.166 & $* * *$ \\
\hline Satisfaction-current-mode $\longleftrightarrow$ Driver-licensure & 0.078 & 0.317 & 0.010 & 7.836 & $* * *$ \\
\hline Comfort-travel-priority $\longleftrightarrow$ Driver-licensure & 0.022 & 0.110 & 0.006 & 3.508 & $* * *$ \\
\hline Comfort-travel-priority $\longleftrightarrow$ Privacy-travel-priority & 0.073 & 0.362 & 0.008 & 8.710 & $* * *$ \\
\hline Comfort-travel-priority $\longleftrightarrow$ Affordability-travel-priority & 0.047 & 0.264 & 0.007 & 6.519 & $* * *$ \\
\hline Comfort-travel-priority $\longleftrightarrow$ Speed-travel-priority & 0.061 & 0.413 & 0.006 & 9.758 & $* * *$ \\
\hline Speed-travel-priority $\longleftrightarrow$ Privacy-travel-priority & 0.056 & 0.317 & 0.007 & 7.680 & $* * *$ \\
\hline Privacy-travel-priority $\longleftrightarrow$ Flexibility-travel-priority & 0.086 & 0.402 & 0.009 & 9.489 & $* * *$ \\
\hline Comfort-travel-priority $\longleftrightarrow$ Flexibility-travel-priority & 0.096 & 0.542 & 0.008 & 12.178 & $* * *$ \\
\hline Comfort-travel-priority $\longleftrightarrow$ Car-ownership & 0.015 & 0.083 & 0.006 & 2.656 & 0.008 \\
\hline Affordability-travel-priority $\longleftrightarrow$ Speed-travel-priority & 0.033 & 0.212 & 0.006 & 5.263 & $* * *$ \\
\hline Trust-of-stewardship $\longleftrightarrow$ Education & 0.016 & 0.060 & 0.009 & 1.720 & 0.045 \\
\hline Education $\longleftrightarrow$ Driver-licensure & 0.052 & 0.191 & 0.010 & 5.102 & $* * *$ \\
\hline
\end{tabular}


Table 3 (continued)

\begin{tabular}{llllll} 
Correlations and covariance & Cov & Corr & SE & CR & P \\
\hline Education $\longleftrightarrow$ Environmental-attitude & 0.012 & 0.088 & 0.006 & 1.833 & 0.067 \\
Car-ownership $\longleftrightarrow$ Education & 0.059 & 0.234 & 0.009 & 6.481 & $* * *$ \\
Car-ownership $\longleftrightarrow$ Driver-licensure & 0.130 & 0.575 & 0.010 & 12.818 & $* * *$ \\
\hline
\end{tabular}

$\beta=$ Unstandardized regression estimates, $b=$ standardized regression estimates; cov covariance, corr correlation; $* * * P$ value $<0.01$

trust of good stewardship from other participants in car-sharing correlates positively with perceived innovation characteristics of car-sharing, and perceived benefits of car-sharing. There is also a small but statistically significant association between educational attainments and trust in car sharing with other people, suggesting that individuals with higher levels of education are more accepting of the idea that car sharing with strangers would bring about good stewardship standards. We also established positive associations among the individual variables measuring our respondents' expectations regarding their daily commuting, namely comfortability, flexibility, affordability and privacy. This finding suggests that these individual items are indeed evaluated together as a bundle of considerations that individuals expect and prioritize in their daily travel choices. Finally, our results show that car-ownership correlates positively with higher levels of education, and an individual's overall satisfaction with their daily work/school travel experiences.

In addition to the aforementioned covariations among variables included in the SEM, we found a number of direct predictive effects on individuals' car-sharing adoption intentions. Results of the SEM show that controlling for other variables, perceived benefits of carsharing has the largest, positive effect on individuals' intention to use car-sharing (standardized path co-efficient $=0.690$ ). This suggests, among our respondents, car-sharing adoption intentions increase with positive perception of the benefits of using this new mode of travel. Despite environmental attitudes, technology attitudes and perception of innovation characteristics of car-sharing correlating positively with perceived benefits, these factors do not have statistically significant effects in terms of predicting whether or not an individual would want to use car-sharing service. Furthermore, we found that Uber-experience predicts car-sharing adoption intentions (standardized path co-efficient $=0.114$ ), suggesting that individuals who have used Uber on-demand taxi services in the past are more likely to want to join car-sharing should the service become available in their city. Controlling for other variables, affordability and flexibility as priorities/expectations with regard to travel mode choice have negative predictive effects on car-sharing adoption intentions, while expectations of comfort and travel speed positively predict car-sharing adoption intentions. Our results also show that gender has a negative predictive effective on car-sharing adoption intentions, controlling for other factors in the model. In the context of our model, this finding suggests that females are more likely to not want to participate in a car-sharing scheme. Also, education has a negative predictive effect on adoption intentions. This suggest that individuals in our sample with advance qualifications beyond a bachelor's degree/ diploma are less likely to want to use car-sharing services. Finally, we found that driver's licensure positively predicts car-sharing adoption intentions, implying that young adults in our sample, who have obtained a driver's licence, but do not necessarily own a car currently, are more likely to want to participate in car-sharing. 


\section{Discussion of findings and policy implications}

In this paper, we have examined the factors behind young adults' intention to use carsharing services in Ghana. We have deployed a conceptual framework that integrates individuals' perception of the benefits of car-sharing, attitudes towards the environment and technology, trust of stewardship in car-sharing, perception of innovativeness of car-sharing, travel expectations and socio-demographic factors to understand whether or not our study participants would use car-sharing services. We first explored our participants' responses to a range of items which we formulated based on our conceptual framework, and subsequently brought all the variables together to specify a structural equation model of carsharing adoption intentions.

The results show that overall, the majority of our respondents recognize car-sharing would bring a number of benefits, including reducing car-ownership and congestion, being suitable for work and non-work journeys and reducing spending on travel. We also found general positive attitude towards the environment and technology, and the perception that car-sharing is an innovative model of urban transportation. From the SEM, we found that individuals with pro-technology and pro-environmental attitudes also tend to agree that car-sharing could lead to positive commuting and environmental outcomes. Findings of previous research (Burkhardt and Millard-Ball 2006; Efthymiou et al. 2013; Becker et al. 2017) show that pro-technology attitudes, which partly reflect openness to new ideas, tend to have positive association with intended adoption and/or use of car-sharing services. As Becker et al. (2017) found, patronage of car-sharing services tends to be influenced, partly, by readiness to accept new innovations. Results of our analysis further show that individuals who agree that car-sharing is an innovative alternative of commuting also recognize that using the service would, overall, yield positive outcomes. Perhaps, more important is our finding that, perceived benefits predict adoption intentions, implying that individuals with positive perceptions about the likely benefits of car-sharing are more likely to want to use the service if it becomes available in their city.

Moreover, we found that while the majority of our respondent indicated not knowing about car-sharing prior to filling in the survey for this research, some of them have in the past used Uber on-demand taxi services in their city. Including this past experience as a predictor variable in our model, we established that it has a positive predictive effect on adoption intentions, suggesting that individuals who have used Uber on-demand taxi services in the past are more likely to want to join car-sharing, controlling for other factors.

Two socio-demographic factors in our model, namely gender and education have statistically significant explanatory effect on car-sharing adoption intention. Our findings suggest that females are less likely to want to participate in car-sharing. Previous studies have arrived at a similar conclusion that that being male significantly increases the probability to want to car-share (Prieto et al. 2017) or use car-sharing services where they are available (Burkhardt and Millard-Ball 2006). The effect of education on adoption intentions in our study is negative. While this finding contradicts previous findings that young and highly educated individuals tend to use car-sharing more (see e.g. Le Vine et al. 2014; Efthymiou et al. 2013; Bardhi and Eckhardt 2012; Prieto et al. 2017), in the context of our study it has to be interpreted carefully. This is because, as the results of the survey have shown, the majority of our respondents have higher level education qualifications. In our model, based on the coding of education variable, the above finding means that the effect of education on adoption intention turns negative as education increases towards advanced degrees (i.e. master's degree or higher). Thus, there appears to be a threshold point for educational 
attainments in our model, which is a bachelor's degree/diploma, beyond which its effect on intention to use car-sharing becomes negative. Indeed, from the analysis, we established that car-ownership is positively correlated with higher education, and that car-owners are more satisfied with their travel mode than public transit users, for example. That more highly educated individuals in our sample already own cars and are more satisfied using a private car, could, therefore, explain why they are less likely to want to car-share.

Our model also examined the effect on car-sharing adoption intention of driver's licensure, controlling for other factors. We found a positive predictive effect, which implies that individuals who have obtained a driver's license are more likely to want to participate in car-sharing. In the context of our study, we explain this finding as follow: We found that while nearly half of our respondents reported having a valid driver's license, less than a quarter of them actually owned a car, probably because they cannot afford to do so. Driving licensure reflects aspirations to drive, and has been found to be a key predictor of caruse (Bailey et al. 2016; Kar et al. 2017). Thus, coupled with the fact that the majority of non-car users are dissatisfied with the poor quality of existing public transport services, this finding could reflect the possibility that people who can drive, but do not necessarily own cars, find being able to bridge the gap between their travel expectations on the one hand and their experiences using public transit on the other hand, by using car-sharing services. Indeed, as our findings show, expectation of comfort and travel speed in relation to travel mode choice, which existing public transit services are failing to provide, positively predict car-sharing adoption intentions.

Last but not least, we found that there exists an interest in both station-based and freefloating car-sharing services among would-be users of car-sharing. Further exploration of our respondents' interests shows that the number of individuals who would definitely use a free-floating service is higher than those who would definitely use a station-based service. This finding could implicitly reflect the recognition that the former would be more convenient, as they would not be required, after use, to return the car to the same station. Also, about two-thirds of would-be users indicated wanting to join car-sharing services within the first 1 year of its introduction, suggesting a potentially lager early-adopter threshold population that could provide the critical mass needed to sustain the service.

The findings of this research have specific implications for transportation policy and practice in Ghana and other developing countries. The first implication of the study derives from our finding on the overall positive attitude towards car-sharing among the respondents. In particular, the underlying positive environmental attitudes point to a possible behaviour change preparedness towards embracing car-sharing, as a potentially environmentally-friendly alternative to car-ownership. Moreover, as lessons from other countries have shown, for collaborative consumption systems such as car-sharing to be viable, a critical mass of users, is critical. In this regard, urban transport policy could leverage the positive attitudes towards car-sharing revealed in this study to introduce car-sharing systems, with the aim to ultimately reducing car ownership.

Furthermore, the findings of this study have practical implications for the implementation of car-sharing as well as the interaction of this new mobility solution with conventional public transport in Ghana and other developing countries. Firstly, we have argued that given the relatively shorter distances covered by suburban to inner-city and within inner-city trips in urban Ghana, the potential exists for car-sharing to meet both commuting and non-commuting trip purposes. As our findings show, more individuals would want to use a free-floating service, implying that it would probably be ideal for city authorities to implement flexible free-floating car-sharing systems, in order to increase service use for commuting trips in particular. 
However, within the broader imperative of achieving sustainable urban mobility, carsharing must not be seen as a solution separate from other travel demand management strategies. Instead, car-sharing must be accompanied by and integrated into an efficient and affordable public transit system. This is particularly crucial in the context of the findings of this study, which suggest that public transit users, the majority of whom are dissatisfied with the existing services, are more likely to want to car-share. Thus, without adequate investment in public transit, the experience-expectation gap in peoples' daily travel mode choices could see more people using low-occupancy car-sharing services instead of public transport. This could offset any positive sustainability benefits that car-sharing might bring in the long term.

\section{Conclusion and limitations}

This study has contributed to filling a major gap in the literature around car-sharing adoption factors by focusing on Ghana, a developing country in Sub-Saharan Africa. We have examined the interplay among a number of factors, including socio-demographic characteristics, perceived benefits of car-sharing, environmental attitudes and experience-expectations gaps regarding existing travel options in shaping car-sharing adoption intentions. We have also outlined practical policy applications of the research findings. Despite the contributions of the current study, there are some limitation worth highlighting. The current research focused on young adults as one of the potential groups of car-sharers. Given that this is only sub-group of the population, it would be useful for future work to explore car-sharing attitudes and use intentions in the general population. It would also be worth exploring the topic in multiple developing countries to derive comparative understanding of public perceptions and attitudes, and the implications for implementing shared-mobility systems in these contexts.

Authors' contribution RAA Conceptualized study, questionnaire design, data collection, statistical analysis, manuscript writing and editing. AS Data collection, statistical analysis, literature search and review, manuscript editing.

\section{Compliance with ethical standards}

Conflict of interest Authors declare that they have no conflict of interest.

Open Access This article is distributed under the terms of the Creative Commons Attribution 4.0 International License (http://creativecommons.org/licenses/by/4.0/), which permits unrestricted use, distribution, and reproduction in any medium, provided you give appropriate credit to the original author(s) and the source, provide a link to the Creative Commons license, and indicate if changes were made.

\section{References}

Abane, A.M.: Travel behaviour in Ghana: empirical observations from four metropolitan areas. J. Transp. Geogr. 19(2), 313-322 (2011)

Acheampong, R.A., Agyemang, F.S., Abdul-Fatawu, M.: Quantifying the spatio-temporal patterns of settlement growth in a metropolitan region of Ghana. GeoJournal 82(4), 823-840 (2017) 
Acheampong, R.A.: Understanding the Co-emergence of Urban Location Choice and Mobility Patterns: Empirical Studies and an Integrated Geospatial and Agent-based Model (Doctoral thesis, University of Cambridge). (2017). https://doi.org/10.17863/CAM.13849

Adarkwa, K.K., Poku-Boansi, M.: Rising vehicle ownership, roadway challenges and traffic congestion in Kumasi. In: Adarkwa, K.K. (ed.) Future of the Tree: Towards Growth and Development of Kumasi, pp. 128-152. University Printing Press, KNUST, Kumasi (2011)

Agyemang, E.: Mode choice for long distance trips: evidence from the Greater Accra Metropolitan Area of Ghana. J. Transp. Geogr. 64, 150-157 (2017)

Ajzen, I.: The theory of planned behaviour. Organ. Behav. Hum. Decis. Process. 50, 179-211 (1991)

Amoh-Gyimah, R., Aidoo, E.N.: Mode of transport to work by government employees in the Kumasi metropolis, Ghana. J. Transp. Geogr. 31, 35-43 (2013)

Armah, F.A., Yawson, D.O., Pappoe, A.A.: A systems dynamics approach to explore traffic congestion and air pollution link in the city of Accra. Ghana. Sustain. 2(1), 252-265 (2010)

Armitage, C.J., Conner, M.: Efficacy of the theory of planned behaviour: a meta-analytic review. Br. J. Soc. Psychol. 40, 471-499 (2001)

Anthes, E.: Mental health: there's an app for that. Nature 532, 20-23 (2016)

Bailey, T.J., Wundersitz, L., Raftery, S.J., Baldock, M.R., Smith, R.: Changing licensing trends and travel mode choices of young adults. J. Australas. Coll. Road Saf. 27(4), 22 (2016)

Bardhi, F., Eckhardt, G.M.: Access-based consumption: the case of car sharing. J. Consum. Res. 39(4), 881-898 (2012)

Barnes, S.J., Mattsson, J.: Understanding current and future issues in collaborative consumption: a fourstage Delphi study. Technol. Forecast. Soc. Chang. 104, 200-211 (2016)

Becker, H., Ciari, F., Axhausen, K.W.: Measuring the car ownership impact of free-floating car-sharing-a case study in Basel, Switzerland. Transp. Res. D Transp. Environ. 65, 51-62 (2018)

Becker, H., Ciari, F., Axhausen, K.W.: Comparing car-sharing schemes in Switzerland: user groups and usage patterns. Transp. Res. A Policy Pract. 97, 17-29 (2017)

Becker, H., Ciari, F., Brignoni, M., Axhausen, K.W.: Impacts of a new free-floating car-sharing system in Basel. In: 14th International Conference on Travel Behaviour Research (IATBR), Windsor (2015)

Botsman, R., Rogers, R.: What's Mine is Yours: The Rise of Collaborative Consumption. Harper Business, New York (2010)

Burkhardt, J., Millard-Ball, A.: Who is attracted to car sharing? Transp. Res. Rec. 1986, 98-105 (2006)

Cervero, R.: Linking urban transport and land use in developing countries. J. Transp. Land Use 6(1), 7-24 (2013)

Cervero, R., Golub, A., Nee, B.: City CarShare: longer-term travel demand and car ownership impacts. Transp. Res. Rec. 1992(1), 70-80 (2007)

Correia, G.H.D.A., Jorge, D.R., Antunes, D.M.: The added value of accounting for users' flexibility and information on the potential of a station-based one-way car-sharing system: an application in Lisbon, Portugal. J. Intell. Transp. Syst. 18(3), 299-308 (2014)

Correia, G., Viegas, J.M.: Carpooling and carpool clubs: clarifying concepts and assessing value enhancement possibilities through a Stated Preference web survey in Lisbon, Portugal. Transp. Res. A: Policy Pract. 45(2), 81-90 (2011)

Davis, F.D.: A technology acceptance model for empirically testing new end-user information systems: theory and results (Doctoral dissertation, Massachusetts Institute of Technology) (1985)

De Lorimier, A., El-Geneidy, A.M.: Understanding the factors affecting vehicle usage and availability in carsharing networks: a case study of Communauto carsharing system from Montréal, Canada. Int. J. Sustain. Transp. 7(1), 35-51 (2013)

Efthymiou, D., Antoniou, C., Waddell, P.: Factors affecting the adoption of vehicle sharing systems by young drivers. Transp. Policy 29, 64-73 (2013)

Esson, J., Gough, K.V., Simon, D., Amankwaa, E.F., Ninot, O., Yankson, P.W.: Livelihoods in motion: linking transport, mobility and income-generating activities. J. Transp. Geogr. 55, 182-188 (2016)

Environmental Protection Agency (EPA). Washington, DC (2015). http://www3.epa.gov/climatechange/ ghgemissions/global.html. Accessed 10 Nov 2015

Ferrero, F., Perboli, G., Rosano, M., Vesco, A.: Car-sharing services: an annotated review. Sustain Cities Soc. (2017). https://doi.org/10.1016/j.scs.2017.09.020

Firnkorn, J., Müller, M.: What will be the environmental effects of new free-floating car-sharing systems? The case of car2go in Ulm. Ecol. Econ. 70(8), 1519-1528 (2011)

Ghana Statistical Service. Ghana Living Standards Survey, Round 6, (2014) http://www.statsghana.gov.gh/ docfiles/glss6/GLSS6_Main\%20Report.pdf. Accessed 20 June 2016

Hamari, J., Sjöklint, M., Ukkonen, A.: The sharing economy: why people participate in collaborative consumption. J. Assoc. Inf. Sci. Technol. 67(9), 2047-2059 (2016) 
Hartl, B., Hofmann, E., Kirchler, E.: Do we need rules for “what's mine is yours”? Governance in collaborative consumption communities. J. Bus. Res. 69(8), 2756-2763 (2016)

Hietanen, S.: "Mobility as a Service"- the new transport model? Eurotransport 12(2), 2-4 (2014)

Holmberg, P.-E., Collado, M., Sarasini, S., Williander, M.: Mobility as a Service-MaaS. Describing the framework (Final report MaaS framework). Göteborg: Viktoria Swedish ICT (2016)

Jittrapirom, P., Caiati, V., Feneri, A.M., Ebrahimigharehbaghi, S., Alonso González, M.J., Narayan, J.: Mobility as a service: a critical review of definitions, assessments of schemes, and key challenges. Urban Plann. (2017). https://doi.org/10.17645/up.v2i2.931

Juschten, M., Ohnmacht, T., Thao, V.T., Gerike, R., Hössinger, R.: Carsharing in Switzerland: identifying new markets by predicting membership based on data on supply and demand. Transportation (2017). https://doi.org/10.1007/s11116-017-9818-7

Kar, I.N., Li, K., Haynie, D.L., Simons-Morton, B.G.: Emerging adults without a driver's license engage in more transportation-related physical activity to school/work in certain environmental contexts. Prev. Med. 96, 42-48 (2017)

Kline, R.B.: Principles and Practice of Structural Equation Modeling, 3rd edn. Guilford, New York (2015)

Kutzbach, M.J.: Motorization in developing countries: causes, consequences, and effectiveness of policy options. J. Urban Econ. 65(2), 154-166 (2009)

Lamberton, C.P., Rose, R.L.: When is ours better than mine? A framework for understanding and altering participation in commercial sharing systems. J. Market. 76(4), 109-125 (2012)

Le Vine, S., Zolfaghari, A., Polak, J.: Carsharing: evolution, challenges and opportunities. In: 22th ACEA Scientific Advisory Group Report, 20ff https://www.acea.be/uploads/publications/SAG_Report_-_ Car_Sharing.pdf (2014). Accessed Aug 2017

Liao, F., Molin, E., Timmermans, H., van Wee, B.: Carsharing: the impact of system characteristics on its potential to replace private car trips and reduce car ownership. Transportation (2018). https://doi. org/10.1007/s11116-018-9929-9

McLaren, D., Agyeman, J.: Sharing Cities: A Case for Truly Smart and Sustainable Cities. MIT Press, Cambridge (2015)

Möhlmann, M.: Collaborative consumption: determinants of satisfaction and the likelihood of using a sharing economy option again. J. Consum. Behav. 14(3), 193-207 (2015)

Mont, O.: Institutionalisation of sustainable consumption patterns based on shared use. Ecol. Econ. 50(1), 135-153 (2004)

Ministry of Transport.: Vehicle Population and Growth Rate. Powerpoint presentation (by Daniel Essel). Retrieved from: http://staging.unep.org/Transport/new/PCFV/pdf/2016Ghana_VehiclePopultaionGro wth.pdf (2016). Accessed 2 Nov 2017

National Communications Authority (NCA).: Quarterly Statistical Bulletin on Communication in Ghana. Second Quarter Volume 1, Issue 2 https://www.nca.org.gh/assets/Uploads/Quaterly-statistics-03-1116-fin.pdf (2016)

Nobis, C.: Carsharing as key contribution to multimodal and sustainable mobility behavior: carsharing in Germany. Transp. Res. Rec. 1986, 89-97 (2006)

Obeng-Odoom, F.: Drive left, look right: the political economy of urban transport in Ghana. Int. J. Urban Sustain. Dev. 1(1-2), 33-48 (2010)

Ohta, H., Fujii, S., Nishimura, Y., Kozuka, M.: Analysis of the acceptance of carsharing and eco-cars in Japan. Int. J. Sustain. Transp. 7(6), 449-467 (2013)

Peprah, C., Amponsah, O., Oduro, C.: A system view of smart mobility and its implications for smart mobility in Ghanaian Cities. Sustain. Cities Soc. (2018). https://doi.org/10.1016/j.scs.2018.10.025

Prieto, M., Baltas, G., Stan, V.: Car sharing adoption intention in urban areas: what are the key sociodemographic drivers? Transp. Res. A Policy Pract. 101, 218-227 (2017)

Rifkin, J.: The Age of Access: The New Culture of Hypercapitalism. Penguin, New York (2001)

Rodier, C.: Review of the international modelling literature: transit, land use, and auto pricing strategies to reduce vehicle miles traveled and greenhouse gas emissions. Transportation Research Record: Journal of the Transportation Research Board, No. 2123, Transportation Research Board of the National Academies, Washington, DC, pp. 1-12 (2009)

Rogers, E.M.: Diffusion of Innovations. The Free Press, New York (2000)

Schaefers, T.: Exploring carsharing usage motives: a hierarchical means-end chain analysis. Transp. Res. A Policy Pract. 47, 69-77 (2013)

Shaheen, S.A., Cohen, A.P.: Carsharing and personal vehicle services: worldwide market developments and emerging trends. Int. J. Sustain. Transp. 7(1), 5-34 (2013)

Shaheen, S.A., Martin, E.: Demand for carsharing systems in Beijing, China: an exploratory study. Int. J. Sustain. Transp. 4(1), 41-55 (2010) 
Sims R., Schaeffer, R., Creutzig, F., Cruz-Núñez, X., D’Agosto, M., Dimitriu, D., Figueroa Meza, M.J., Fulton, L., Kobayashi, S., Lah, O., McKinnon, A., Newman, P., Ouyang, M., Schauer, J.J., Sperling, D. Tiwari, G.: Transport. In: Climate Change 2014: Mitigation of Climate Change. Contribution of Working Group III to the Fifth Assessment Report of the Intergovern- mental Panel on Climate Change. Edenhofer et al. (eds) Cambridge University Press, Cambridge, New York, NY (2014)

Sioui, L., Morency, C., Trépanier, M.: How carsharing affects the travel behavior of households: a case study of montréal, Canada. Int. J. Sustain. Transp. 7(1), 52-69 (2013)

Stow, D.A., Weeks, J.R., Toure, S., Coulter, L.L., Lippitt, C.D., Ashcroft, E.: Urban vegetation cover and vegetation change in Accra, Ghana: connection to housing quality. Prof. Geographer 65(3), 451-465 (2013)

Sundararajan, A.: The Sharing Economy: The End of Employment and the Rise of Crowd-Based Capitalism. MIT Press, Cambridge (2016)

World Bank. Project appraisal document on a proposed credit in the amount of SDR 150.5 million (US\$225.0 million equivalent) to the republic of Ghana for a Transport Sector (2009)

Publisher's Note Springer Nature remains neutral with regard to jurisdictional claims in published maps and institutional affiliations.

Ransford A. Acheampong PhD is a Presidential Academic Fellow in Future Cities at the Manchester Urban Institute and the Department of Planning and Environmental Management, University of Manchester. His research interests include understanding user adoption behaviour, diffusion trends and socio-spatial implications of emerging mobility solutions such as shared-mobility, mobility-as-a-service and autonomous transport.

Alhassan Siiba holds an MSc in Transportation Planning from the Institute for Transport Studies (ITS), University of Leeds, UK. His research interests revolve around the intersection of transportation and urban Planning, focusing on issues related to transport disadvantage and social exclusion, active transport (i.e. walking and cycling) and transport and land-use integration for sustainable development.

\section{Affiliations}

\section{Ransford A. Acheampong ${ }^{1}$ (D) Alhassan Siiba ${ }^{2}$}

1 Department of Planning and Environmental Management, Manchester Urban Institute, The University of Manchester, Manchester, UK

2 Institute for Transport Studies (ITS), University of Leeds, Leeds, UK 